\title{
Oxidation and thermal behavior of Jatropha curcas biodiesel influenced by antioxidants and metal contaminants
}

\author{
Siddharth Jain ${ }^{1 *}$, M.P. Sharma \\ ${ }^{1,2}$ Biofuel Research Laboratory, Alternate Hydro Energy Centre, Indian Institute of Technology Roorkee, Roorkee, Uttarakhand- 247667, INDIA \\ "Corresponding Author: e- mail: arthjain2001@gmail.com, Tel.: +91 9456382050; Fax: +91 1332273517
}

\begin{abstract}
According to European biodiesel standard EN-14214 the minimum requirement of oxidation stability in terms of induction period is $6 \mathrm{hr}$ by the Rancimat method (EN-14112). The induction period of fresh Jatropha curcas biodiesel (JCB) is $3.27 \mathrm{hr}$. Also the thermal stability of JCB is very poor in terms of activation energy $\left(E_{a}\right)$ and frequency factor (f). The thermal and oxidation behavior is also affected adversely by the container metal. The present paper is dealing with the study of oxidation and thermal behavior of JCB with respect to different metal contents. It was found that influence of metal was detrimental to thermal and oxidation stability. Even small concentrations of metal contaminants showed nearly same influence on oxidation stability as large amounts. Copper $(\mathrm{Cu})$ showed strongest detrimental effect on both, oxidation and thermal stability. Relative effectiveness of different antioxidants were also checked and found that pyrogallol (PY) is the most effective one. The effect of PY is studied in metal contaminated JCB to see the oxidation and thermal stability.
\end{abstract}

Keywords: Jatropha curcas biodiesel (JCB), thermal stability, rancimat, TGA, activation energy, methyl ester (ME), metal contaminate.

\section{Introduction}

Nowadays, biodiesel is considered as an important alternative biofuel due to its environmental benefits and simple industrial production from renewable resources. Biodiesel has the added advantage of higher lubricity compared to petro-diesel. However, such ecofriendly liquid fuels have lower oxidation stability and low processing temperature (Jain and Sharma, 2010a). The biodiesel has the same fatty acids compositions similar to the parent oils or fatties with considerable amount of unsaturated fatty acids. Its oxidative stability, therefore, becomes crucial quality issue during long term storage (Jain and Sharma, 2010b; Dunn, 2006). A number of research groups are working to find out the substances that inhibit this oxidation process and maintain the quality of biodiesel (Jain and Sharma, 2010b; Jain and Sharma, 2010c). Several vegetable oils obtained from soybean, castor, sunflower, cotton, corn, palm, etc are widely used for biodiesel production in different parts of the world depending on the cultivation of oil crop. India imports about $40-50 \%$ edible oil of its total domestic demand (Jain and Sharma, 2010a; Jain and Sharma, 2008) and therefore, it is impossible to divert these edible oil resources for biodiesel production and attention has therefore been directed to the use of non-edible oil resources like Jatropha, pongamia, neem etc for biodiesel production in the country. Jatropha curcas is a drought-resistant perennial, growing well in marginal/poor soil. It is easy to establish, grows relatively quickly and lives, producing seeds for 50 years. Jatropha the wonder plant produces seeds with an oil content of $37 \%$. The oil can be combusted as fuel without being refined. It burns with clear smoke-free flame, tested successfully as fuel for simple diesel engine (Jingura et al., 2010). Biodiesel consists of long chain fatty acid esters derived from feedstocks such as vegetable oils, animal fats, used frying oil etc. which may contain more or less unsaturated fatty acids which are prone to oxidation accelerated by exposure to air during storage and may yield polymerized compounds at high temperature (Jain and Sharma, 2010b). Also while using biodiesel in engine; it is subjected to higher temperatures before and during combustion. This high temperature conditions favors the deterioration of biodiesel and form deposits and insolubles in the fuel resulting in the choking of filter pipe lines, fuel pump pipe lines thereby impacting the combustion process due to reduction in combustion area. All these problems ultimately reduce the engine efficiency as well as its life (Jain and Sharma, 2010b). It has been reported that the 
oxidation stability of easily oxidized biodiesel can be maintained near to stability specification by adding / mixing antioxidants/ additives in optimum concentration.

Although there are numerous papers available on the storage, thermal and oxidation stability of biodiesel and effect of antioxidants on the stability of biodiesel synthesized from edible oils but little work is available on oxidation and thermal stability of biodiesel from non-edible oil seeds and on influence of presence of metal on oxidation and thermal behavior of biodiesel from non-edible oil seeds. Mittelbach and Schober (2003) has further studied the influence of antioxidants on the oxidation stability of biodiesel and showed the influence of different synthetic and natural antioxidants on the oxidation stability using the specified test method. Dunn (2005) examined the effectiveness of five synthetic antioxidants in mixtures with soybean oil fatty acid methyl esters (SME) and found that increasing antioxidant loading (concentration) increases the activity also. Sarin et al. (2007) have experimented on JCB and found an optimum mix for Asia using different blends of biodiesel from palm and Jatropha oil for improved oxidation stability. Liang et al. (2006) have examined the effect of natural and synthetic antioxidants on the oxidative stability of palm diesel. Sarin et al. (2009) have evaluated the influence of metal contaminants on oxidation stability of Jatropha biodiesel. From the experiment it was found that influence of metal was detrimental to oxidation stability. Even small concentrations of metal contaminants showed nearly same influence on oxidation stability as large amounts. Copper showed strongest detrimental and catalytic effect. Fritsch et al. (1975) have examined the effect of antioxidants on refined palm oil and found TBHQ to have better effect as antioxidant on refined palm oil than BHT and BHA.

The enhancement of biodiesel stability by this way has been widely studied, but the effect of thermal degradation and its kinetic behavior through thermogravimetric analysis (TGA) has not yet been reported (Jain and Sharma, 2010b). Chand et al. (2009) studied the effectiveness of TGA and found that TGA is an effective method, which is typically within $\pm 1.5 \%$ relative to proton NMR method. Dantas et al. (2007) studied the thermal stability and decomposition of biodiesel using TGA - DTA curves obtained using a simultaneous DTA/TG analyzer (SDT 2960, TA Instruments) in air and nitrogen (100 $\mathrm{ml} / \mathrm{min}$ flow rate) in the temperature range $30^{\circ}-600^{\circ} \mathrm{C}$ at a heating rate of $10^{\circ} \mathrm{C} / \mathrm{min}$ using about $20 \mathrm{mg}$ of sample in alumina crucible. The kinetics of corn biodiesel, obtained from both the methanol and ethanol routes, was conducted using dynamic heating to determine the mechanism, kinetic parameters and reaction order $(n)$ and apparent activation energy $\left(E_{a}\right)$. Wan Nik et al. (2005) studied the thermal stability of palm oil as energy transport media in a hydraulic system In this study, two models were used to evaluate the kinetic parameters of the oil samples as direct Arrhenius plot method and integration method. Freire et al. (2009) evaluated the thermal behavior of the physic nut oil and biodiesel from several Brazilian crops using thermoanalytical techniques. Thermogravimetry (TG) and pressurized-differential scanning calorimetry (PDSC) were used to determine the applicability of physic nut biodiesel. Results suggested the physic nut biodiesel, as a prospective, renewable and biodegradable fuel for use in diesel engines. The results have also shown that with increase in oxidation of biodiesel, the onset temperature decreases resulting in reduced fuel stability.

The objective of this study is to investigate the influence of presence of metals on the oxidation and thermal behavior of JCB and also to investigate the effect of antioxidants on the oxidation and thermal behavior of metal doped JCB. Different transition metals - iron, nickel, manganese, cobalt, and copper, commonly found in metallurgy of storage tanks and barrels, were blended with varying concentrations (parts per million (ppm)) in JCB.

\section{Materials}

Butylated hydroxytoluene (BHT), tert-butyl hydroquinone (TBHQ), butylated hydroxyanisole (BHA), propyl gallate (PG), and pyrogallol (PY) were the additives employed for evaluating their effect on the stability of biodiesel and its blends with diesel. All chemicals were of analytical grade (AR) and purchased from Sigma Aldrich, India. Different transition metals - iron, nickel, manganese, cobalt, and copper have also been purchased from Sigma Aldrich, India. Biodiesel was prepared using different methodology from Jatropha curcas oil (JCO), will be discussed in the experimental section. The blends of JCB with diesel having pre-decided concentration of additives/ antioxidants were used.

\section{Experimental}

\subsection{Biodiesel preparation}

Since the initial FFA contents of JCO was very high (15.4\%), a two step acid- base catalyzed transesterification process is used to prepare the biodiesel as per the method reported in our paper (Jain and Sharma, 2010d). Fatty acid composition of biodiesel was analyzed using Gas chromatograph [DIN EN 14103, 2003] and is given in Table 1 which shows that the JCB is maximum composed of unsaturated fatty acids (75.3\%) responsible for poor oxidation and thermal stability of biodiesel.

The biodiesel samples prepared above were tested for physico- chemical properties as per ASTM D-6751 and Indian IS- 15607 specification given in Table 2 which shows that the biodiesel prepared from JCO meet most of the specifications except oxidation stability test. 
Table 1: Fatty acid composition of JCB

\begin{tabular}{|c|c|c|c|}
\hline Fatty Acid & Molecular Formula & Chemical structure & \% Composition \\
\hline Palmitic acid (P) & $\mathrm{C}_{16} \mathrm{H}_{32} \mathrm{O}_{2}$ & $\mathrm{CH}_{3}\left(\mathrm{CH}_{2}\right)_{14} \mathrm{COOH}$ & 16.8 \\
\hline Stearic acid (S) & $\mathrm{C}_{18} \mathrm{H}_{38} \mathrm{O}_{2}$ & $\mathrm{CH}_{3}\left(\mathrm{CH}_{2}\right)_{16} \mathrm{COOH}$ & 7.7 \\
\hline Oleic acid (O) & $\mathrm{C}_{18} \mathrm{H}_{34} \mathrm{O}_{2}$ & $\mathrm{CH}_{3}\left(\mathrm{CH}_{2}\right)_{7}-\mathrm{CH}=\mathrm{CH}-\left(\mathrm{CH}_{2}\right)_{7} \mathrm{COOH}$ & 39.1 \\
\hline Linoleic acid (L) & $\mathrm{C}_{18} \mathrm{H}_{32} \mathrm{O}_{2}$ & $\mathrm{CH}_{3}\left(\mathrm{CH}_{2}\right)_{4} \mathrm{CH}=\mathrm{CH}-\mathrm{CH}_{2}-\mathrm{CH}=\mathrm{CH}-\left(\mathrm{CH}_{2}\right)_{7}$ & 36.0 \\
& & $\mathrm{COOH}$ & 0.2 \\
\hline Linolenic acid (LL) & $\mathrm{C}_{18} \mathrm{H}_{30} \mathrm{O}_{2}$ & $\mathrm{CH}_{3}\left(\mathrm{CH}_{2}\right)_{4} \mathrm{CH}=\mathrm{CH}-\mathrm{CH}_{2}-\mathrm{CH}=\mathrm{CH}-\mathrm{CH}_{2}-$ & \\
\hline
\end{tabular}

Table 2: ASTM and IS specification of biodiesel

\begin{tabular}{|l|l|l|l|l|l|l|}
\hline S.No. & Property (unit) & ASTM 6751 & $\begin{array}{l}\text { ASTM 6751 } \\
\text { limits }\end{array}$ & IS 15607 & IS 15607 limits & JCB \\
\hline 1 & Flash point $\left({ }^{0} \mathrm{C}\right)$ & D-93 & Min.130 & IS 1448 & & 172 \\
\hline 2 & Viscosity at 40 ${ }^{\circ} \mathrm{C}(\mathrm{cSt})$ & D-445 & $1.9-6.0$ & IS 1448 & & 4.38 \\
\hline 3 & $\begin{array}{l}\text { Water and sediment } \\
\text { (vol\%) }\end{array}$ & D-2709 & Max.0.05 & D-2709 & Max.0.05 & 0.05 \\
\hline 4 & Free glycerin (\% mass) & D-6584 & Max.0.02 & D-6584 & Max.0.02 & 0.01 \\
\hline 5 & Total glycerin (\% mass) & D-6584 & Max.0.24 & D-6584 & Max.0.24 & 0.03 \\
\hline 6 & $\begin{array}{l}\text { Oxidation stability of } \\
\text { FAME, hrs }\end{array}$ & 3 & EN 14112 & Min. 6 & 3.27 \\
\hline 7 & $\begin{array}{l}\text { Oxidation stability of } \\
\text { FAME blend, hrs }\end{array}$ & NA & NA & EN 590 & Min. 20 & NA \\
\hline
\end{tabular}

\subsection{Determination of thermal stability}

The thermogravimetric (TG) thermogram of JCB was recorded on the thermogravimetric analyser (Perkin Elmer Pyris 6) using alumina pans. The thermal analysis was conducted at a heating rate of $10^{\circ} \mathrm{C} / \mathrm{min}$ from $10^{\circ} \mathrm{C}$ to $700^{\circ} \mathrm{C}$ in a dry air atmosphere of $100 \mathrm{ml} / \mathrm{min}$. A sample size of about $15 \mathrm{mg}$ was used. The temperature and weight scales were calibrated using indium over a specific range of heating rates with a calibration parameter over its respective Curie point.

\subsubsection{Non-isothermal analysis}

Thermogravimetric data has been used to characterize the materials as well as to investigate the thermodynamics and kinetics of the reactions and transitions of oil samples in oil industries. The method can also be adopted to analyse the thermal behavior of biodiesel. Currently, several methods are available in the literature that can be used to calculate the kinetic parameters (Chand et al., 2009). The kinetic analysis used for the thermal conversion of the biodiesel is discussed below:

The rate of conversion, $\mathrm{dx} / \mathrm{dt}$, for the biodiesel conversion is expressed by

$$
\frac{d x}{d t}=k f(x)=k(1-x)^{n}
$$

where $\mathrm{n}$ is the order of reaction, $\mathrm{k}$ is the reaction rate constant and $\mathrm{x}$ is the extent of conversion $\mathrm{x}$ is given by

$$
x=\frac{w_{0}-w_{t}}{w_{0}-w_{\infty}}
$$

where $\mathrm{w}_{\mathrm{o}}$, wt and $\mathrm{w}_{\infty}$ are the original, current and final weights of sample respectively.

Based on the TGA thermogram, reaction (1) was found to be of first order,

Thus $\mathrm{n}=1$ and Eq. (1) becomes 
$\frac{d x}{d t}=k(1-x)$

For the non-isothermal case, the above equation can be further modified to

$$
\frac{d x}{d T} \frac{d T}{d t}=k(1-x)
$$

where $\mathrm{dT} / \mathrm{dt}$ is the heating rate $\mathrm{B}$.

According to the Arrhenius relationship, the reaction rate constant $\mathrm{k}$ in Eq. (2) can be expressed as

$$
k=A e^{-\frac{E a}{R T}}
$$

where, $E_{a}, A$ and $R$ are the activation energy, frequency factor and ideal gas law constant $(8.314 \mathrm{~J} / \mathrm{mol} \mathrm{K})$ respectively.

Substituting Eq. (3) into Eq. (2) yields

$$
\frac{d x}{d t}=\frac{A}{B} \exp \left(-\frac{E_{a}}{R T}\right)(1-x)
$$

For the direct Arrhenius plot method for the non-isothermal kinetic parameters with constant heating rate $(B=d T / d t)$, Eq. (4) was rearranged to

$\ln \left[\frac{1}{(1-x)} \frac{d x}{d t}\right]=\ln \frac{A}{B}-\frac{E_{a}}{R T}$

The plot $\ln [1 /(1-\mathrm{x}) . \mathrm{dx} / \mathrm{dt}]$ versus $1 / \mathrm{T}$ should give a straight line with slope $-\mathrm{Ea} / \mathrm{R}$, from which the activation energy, $E_{a}$, can be calculated.

\subsection{Determination of oxidation stability}

Oxidation stability of JCB was quantified by the induction period (IP) which was evaluated as per the Rancimat method EN 14112. All stability measurements were carried out on a Metrohm 873 Biodiesel Rancimat instrument. Samples of $3 \mathrm{~g}$ of pure biodiesel were analyzed under a constant air flow of $10 \mathrm{l} / \mathrm{h}$, passing through the fuel and into a vessel containing distilled water. The samples were held at $110^{\circ} \mathrm{C}$ heating block temperature. The electrode is connected to a measuring and recording device. The end of the induction period is indicated when the conductivity starts to increase rapidly. This accelerated increase in conductivity is caused by the dissociation of volatile carboxylic acids produced during the oxidation process and absorbed in the water. When the conductivity of this measuring solution is recorded continuously, an oxidation curve is obtained whose point of inflection is known as the IP.

\section{Result and discussion}

\subsection{Effect of antioxidants on the thermal stability of biodiesel}

Thermogravimetric analysis using the direct Arrhenius plot method has been used by numerous researchers (Chand et al., 2009; Dantas et al., 2007; Freire et al., 2009; Fritsch et al., 1975). Eq. 5 was used to determine the activation energy of the oil samples by the direct Arrhenius plot method. For the fresh JCB sample, the activation energy and the frequency factor were computed to be 39 $\mathrm{kJ} / \mathrm{mol}$ and $6501.48 \mathrm{~min}^{-1}$ respectively. This shows that the fresh JCB is very much susceptible to thermal degradation. This method has been used for oil degradation only but the present paper is used this method for the thermal degradation of CB for the first time. Figure. 1 compares the activation energy and frequency factors respectively for all the fresh JCB with and without additives, respectively. The apparent activation energy of fresh JCB without additive is about $39 \mathrm{~kJ} / \mathrm{mol}$, while the activation energy for the samples with PY added in 300ppm increased up to $80.99 \mathrm{~kJ} / \mathrm{mol}$ showing thereby that PY is a better additive compared to other additives used. The activation energy has a linear relationship with the additive concentration. 


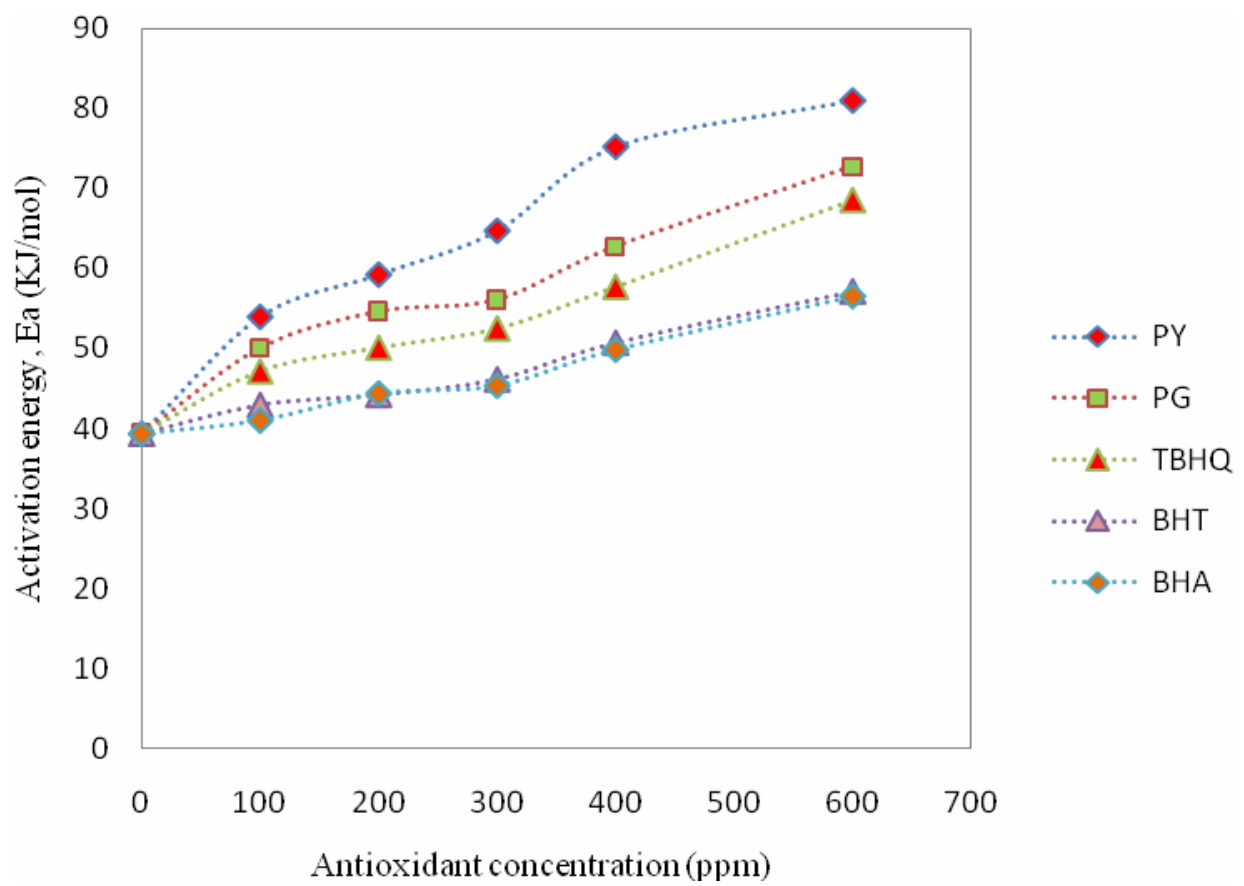

Figure.1 Effect of antioxidants on the activation energy of thermal degradation

The frequency factor has behavior similar to that of activation energy as shown in Figure 2 which has increased from 6501.8 $\min ^{-1}$ without antioxidant to maximum value of $100391198.1 \mathrm{~min}^{-1}$ with PY antioxidant (600ppm). In order to ensure sample temperature uniformity and minimize error, the same sample size $(10 \mathrm{mg})$ was used in the experiments. It is expected that the onset and final temperatures would decrease or increase if smaller or larger sample sizes were used respectively (Chand et al., 2009). Larger sample size means smaller surface exposure per sample volume. This would make the decomposition process slower. The thermal stability of biodiesel could be defined as the resistance to thermal degradation. The higher the temperature, the faster is the oxidation process, i.e. higher rate of degradation of biodiesel.

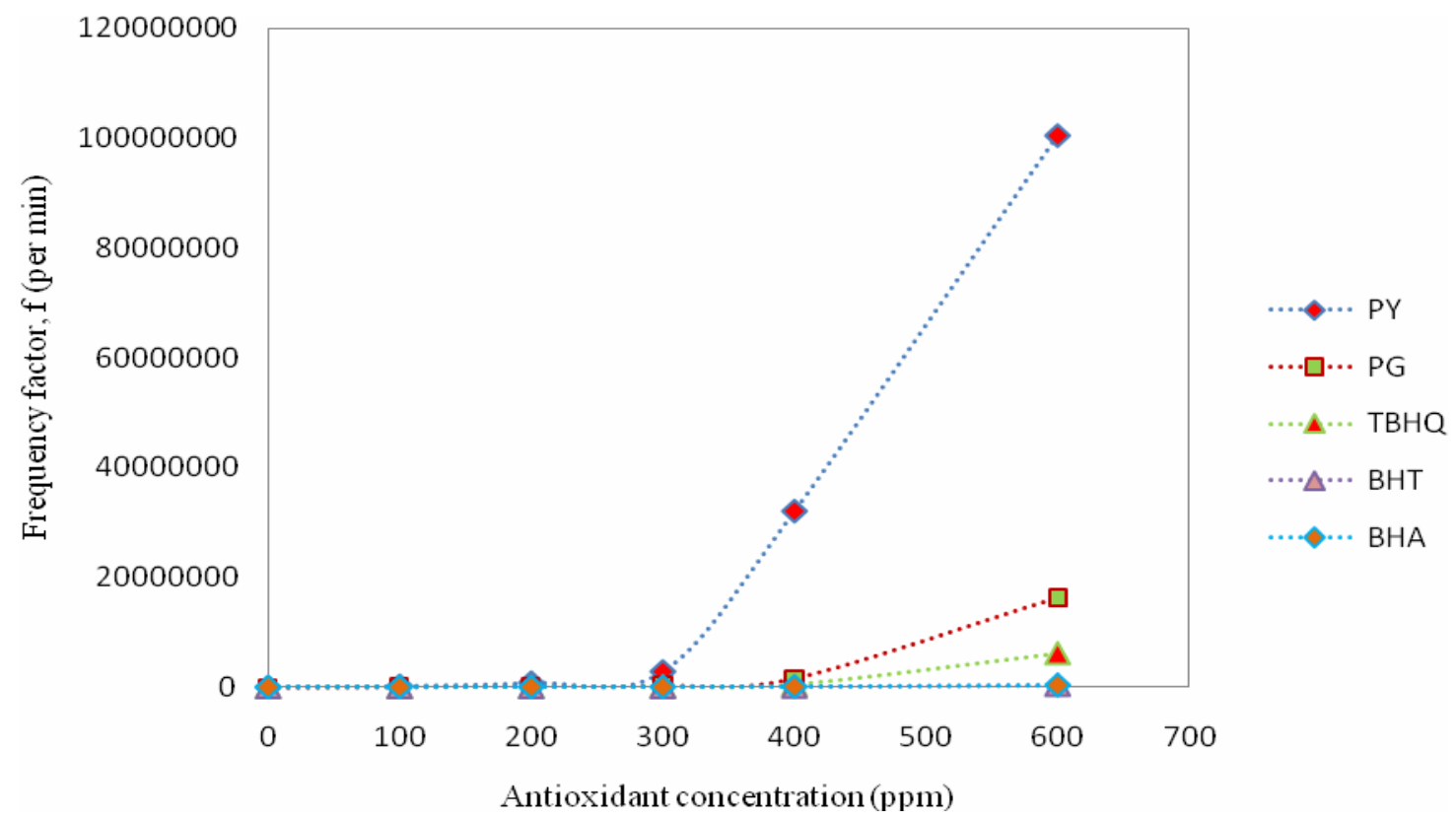

Figure.2 Effect of antioxidants on the frequency factor 


\subsection{Effect of antioxidants on the oxidation stability of fresh JCB}

All the 5 antioxidants were doped at different dosage $(100,200,300,400$ and $600 \mathrm{ppm})$ in JCB and Rancimat test was conducted to study the effectiveness of different antioxidants and the results are given in Figure 3.

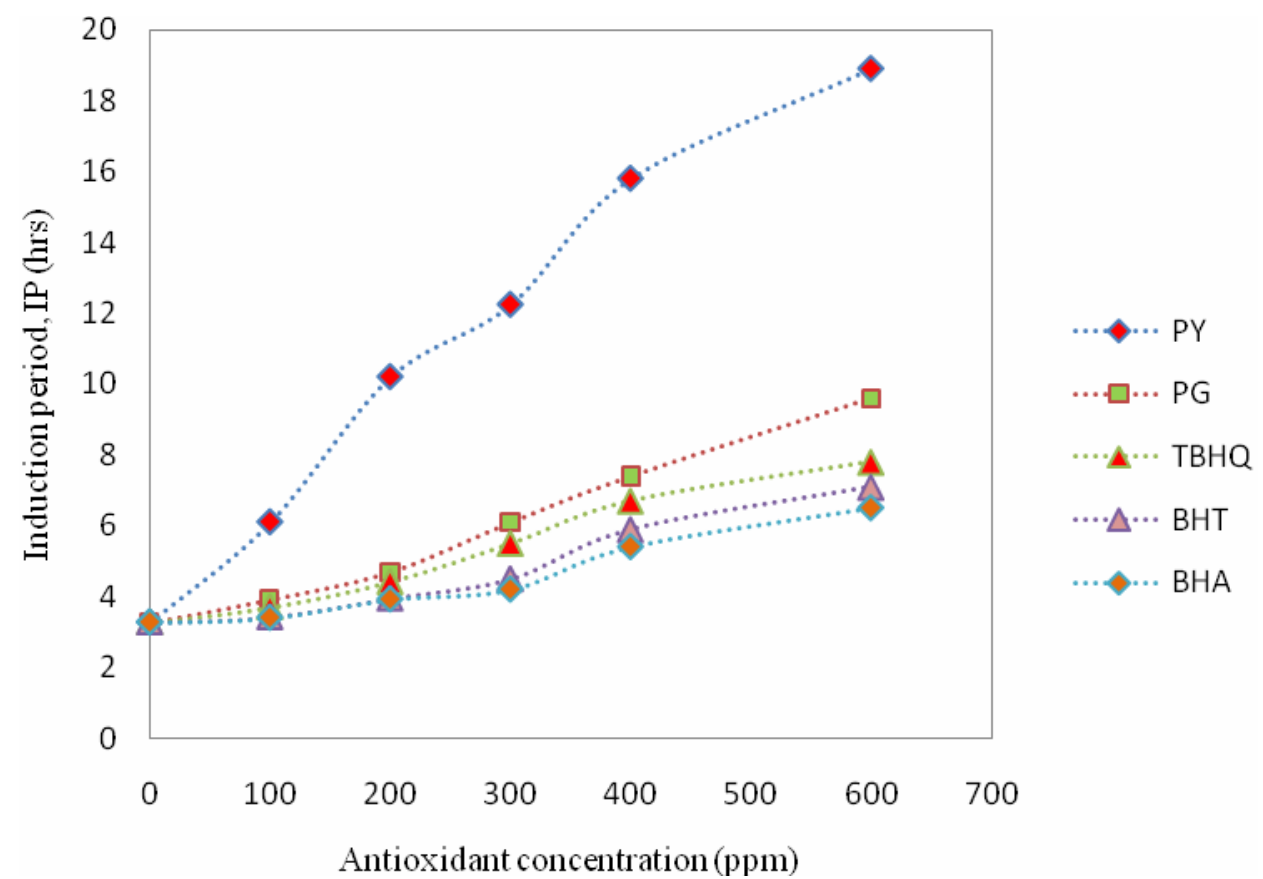

Figure.3 Effect of antioxidants on the oxidation stability of JCB

Figure 3 shows the effect of all phenolic antioxidants from 100 to $600 \mathrm{ppm}$ dosage on the oxidation stability. The oxidation stability of JCB has been found to increase with increase in dosage of antioxidant which is in agreement with the result of the thermal analysis in terms of activation energy, onset temperature and frequency factor. Finally, it is found that dosing of $100 \mathrm{ppm}$ of PY antioxidant is the minimum concentration required to meet EN 14112 specification for biodiesel oxidative stability.

\subsection{Effect of metal contaminants on the oxidation and thermal stability of JCB}

Different transition metals - iron, nickel, manganese, cobalt, and copper, commonly found in metal containers, were blended with varying concentrations (ppm) in JCB samples. Figure. shows that the presence of these metals depressed the oxidation and thermal stability of biodiesel. The presence of metals in biodiesel resulted in acceleration of free radical oxidation due to a metal-mediated initiation reaction. Copper had strongest catalytic effect and other metals - iron, nickel, manganese, and cobalt also had strong negative influence on oxidation and thermal stability. Figure.4, 5 and 6 shows that for all the metal contaminants, induction period, activation energy and frequency factor values respectively. The Figures show that these factors became almost constant as concentration of metal is increased. This proves that the influence of metals was catalytic, as even small concentrations of metals had nearly the same effect on oxidation stability as large amounts. 


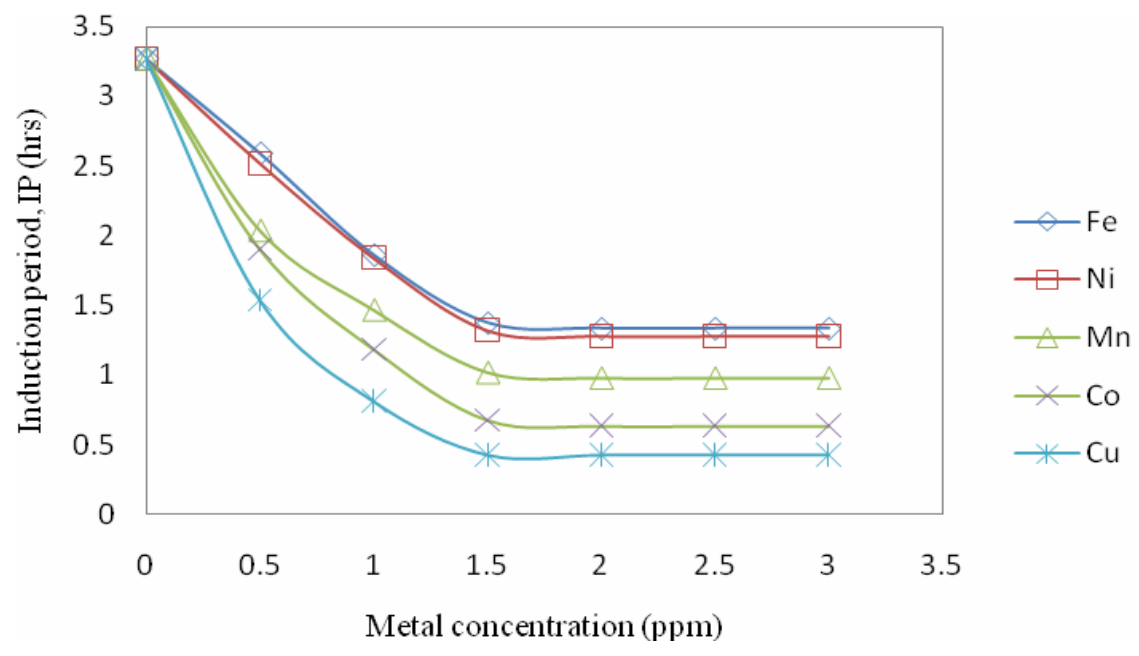

Figure 4. Effect of metal contaminants on IP of JCB

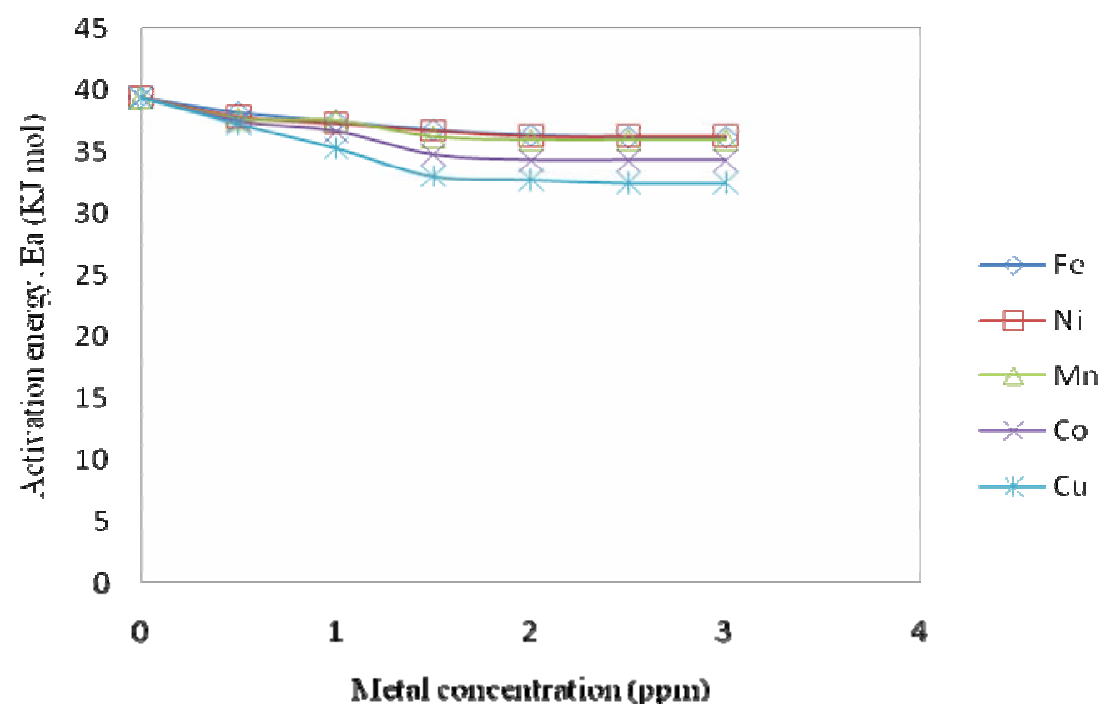

Figure 5. Effect of metal contaminants on activation energy of JCB

\subsection{Improvement of oxidation and thermal stability of metal contaminated JBD}

As it is already observed, PY is the most effective among all the antioxidants used and minimum dose of $100 \mathrm{ppm}$ of PY was needed to improve the IP of neat JBD from $3.27 \mathrm{~h}$ to above $6 \mathrm{~h}$ as required by EN-14112 specification for biodiesel oxidation stability (Figure.3). Therefore, it is decided to study the effect of dosage of PY on oxidation and thermal stability of metal contaminated JCB. PY was doped to the metal contaminated JCB samples with varying concentrations (ppm). The corresponding IPs were measured with the Rancimat test method and TGA method using direct Arrhenius plot method is employed for the measurement of activation energy and frequency factor. As metallic impurities have catalytic effect, 2 ppm metal concentration was selected for antioxidant dose optimization. Figure. shows the variation of IP of $2 \mathrm{ppm}$ metal contaminated JCB with varying concentrations of PY. The oxidation stability of metal contaminated JCB has been found to increase with increase in dosage of antioxidant PY. Finally it is found that minimum $350 \mathrm{ppm}$ dosage of PY was needed to improve the IP of iron and nickel contaminated JCB and minimum dosage of $400 \mathrm{ppm}$ of PY in manganese contaminated JCB was needed to meet EN-14112 specification for biodiesel oxidation stability (Figure. 7). 


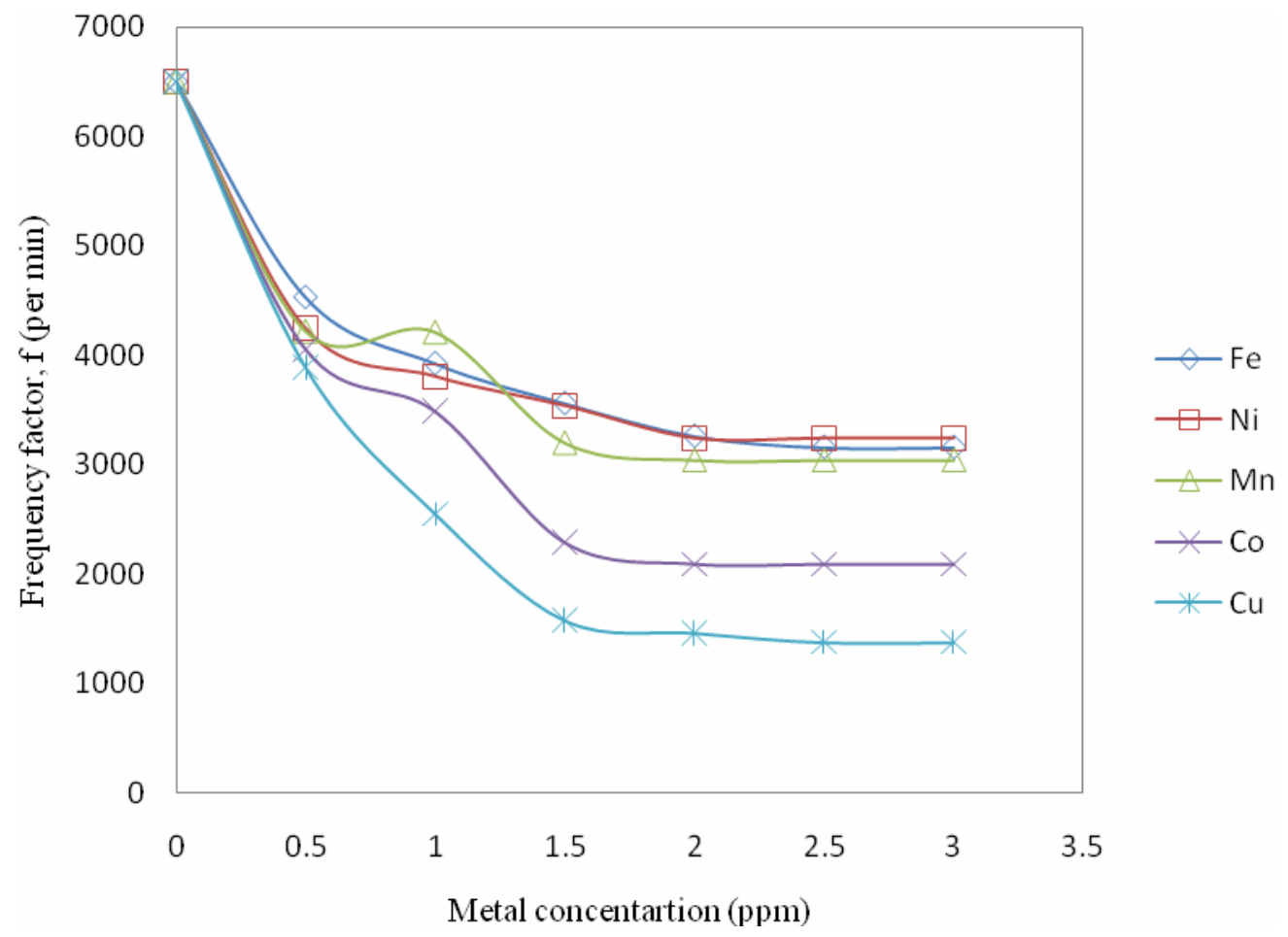

Figure 6. Effect of metal contaminants on frequency factor of JCB

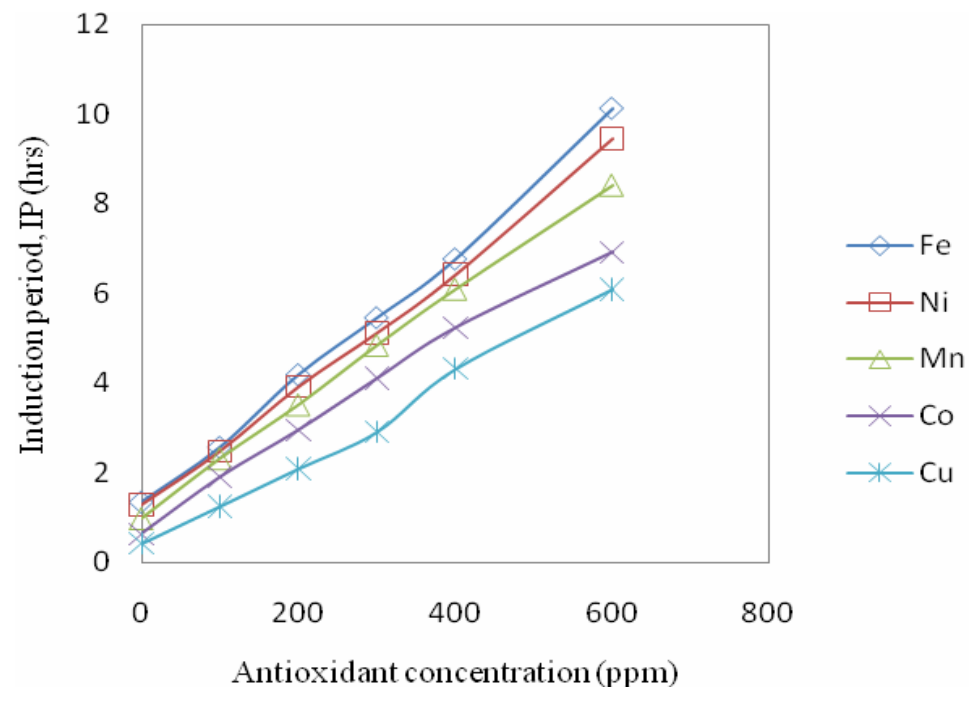

Figure 7. Effect of PY antioxidant on metal contaminated biodiesel in terms of IP 


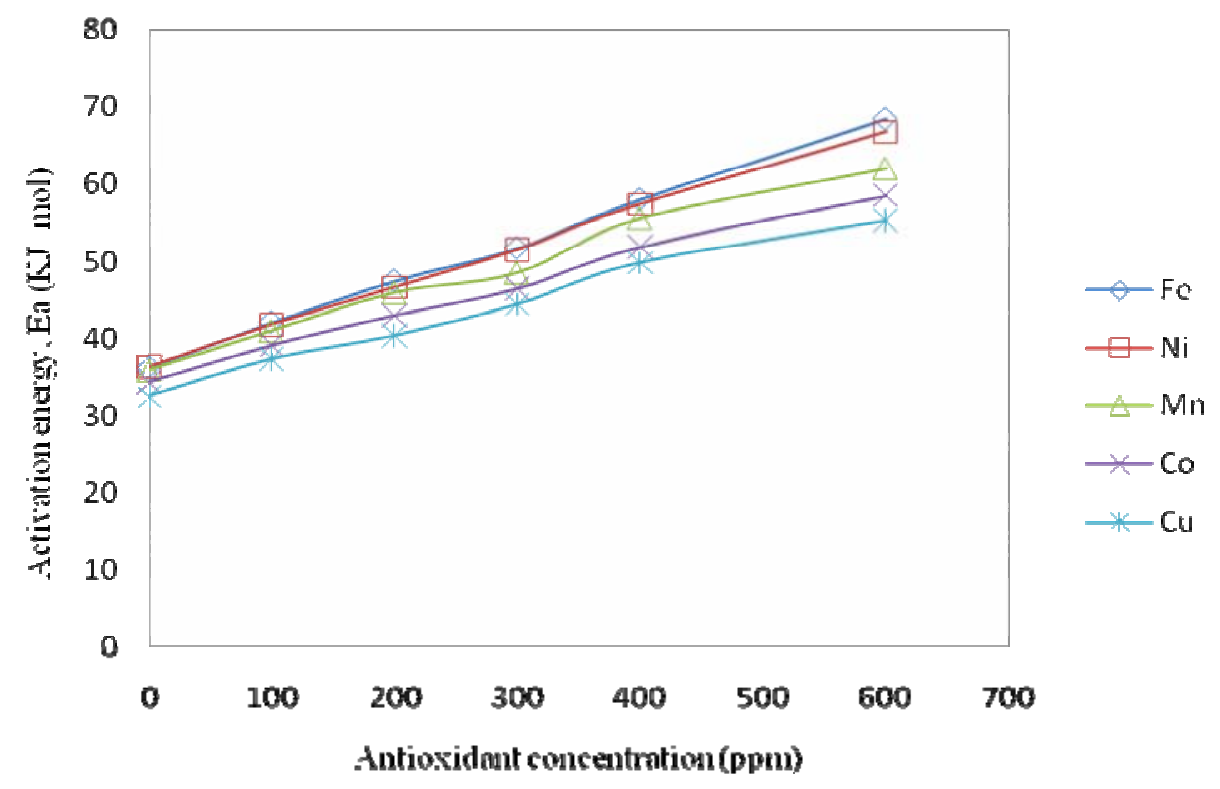

Figure 8. Effect of PY antioxidant on metal contaminated biodiesel in terms of activation energy

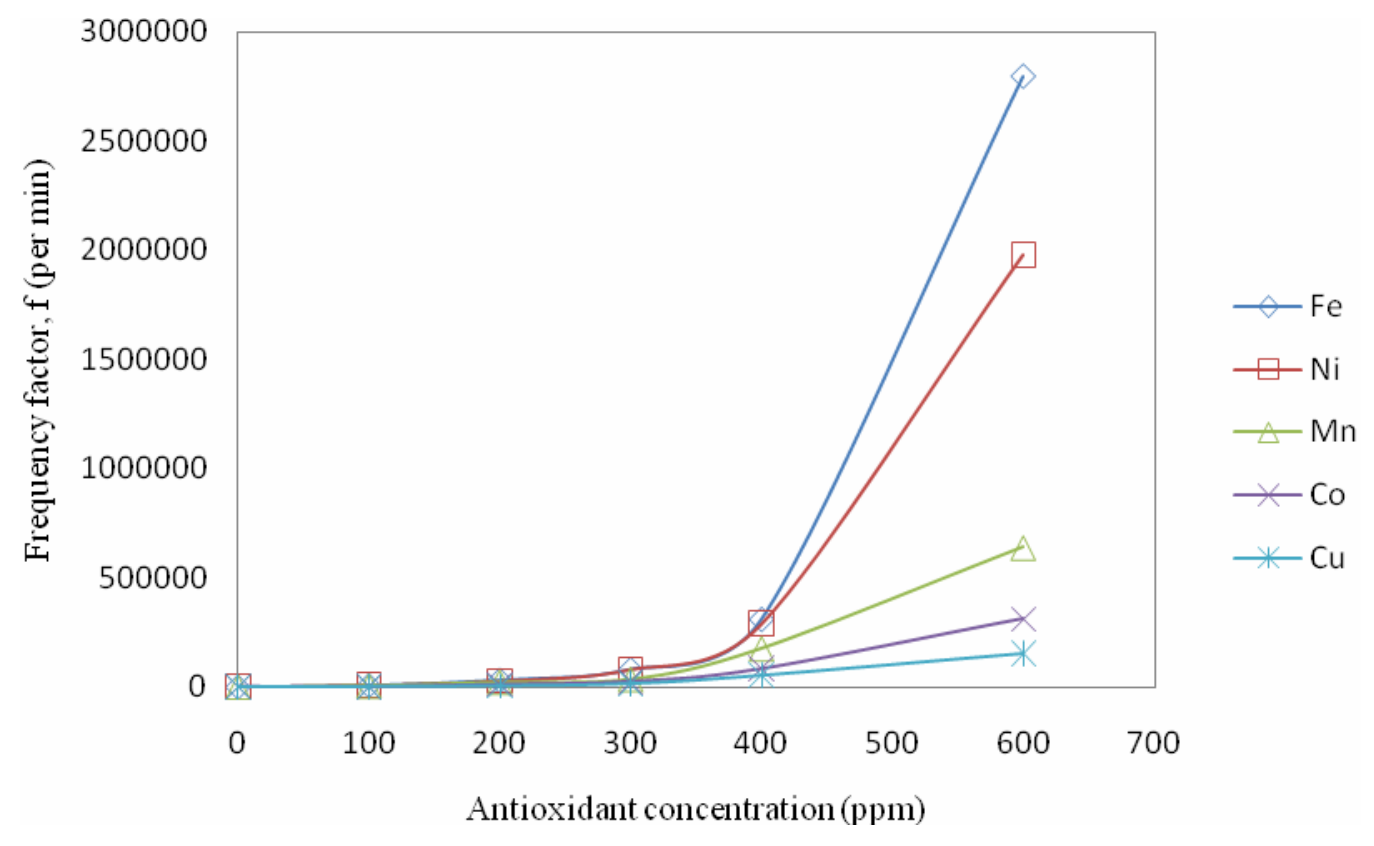

Figure 9. Effect of PY antioxidant on metal contaminated biodiesel in terms of frequency factor

Figure. 7 also shows that for cobalt and copper contaminated JCB, minimum dosages of $600 \mathrm{ppm}$ is required to meet EN-14112 specifications. In the same manner Figure 8 and 9 shows the effect of doping of PY in metal contaminated JCB on activation energy and frequency factor respectively. Figure 8 and 9 also shows the increase in activation energy and frequency factor with the rising concentration of PY. The activation energy was increased from $36.19 \mathrm{KJ} / \mathrm{mol}$ to $68.44 \mathrm{KJ} / \mathrm{mol}$ and frequency factor increases from $3158.6 \mathrm{~min}^{-1}$ to $2792883.39 \mathrm{~min}^{-1}$, as the concentration of PY increases from 0 to $600 \mathrm{ppm}$ in iron contaminated JCB. The corresponding value of activation energy and frequency factor according to IP of $6 \mathrm{hr}$ for iron contaminated JCB is 54 $\mathrm{KJ} / \mathrm{mol}$ and $125000 \mathrm{~min}^{-1}$ respectively. 


\section{Conclusion}

The thermal and oxidation stability of biodiesel was found to be very critical. Biodiesel requires antioxidant to meet oxidation stability requirements. In order to meet EN-14112 specification, minimum dosage of $100 \mathrm{ppm}$ concentration of PY is required for JCB. PY was found to be the most effective antioxidant for oxidation and thermal stability. The oxidation and thermal stability of biodiesel affected adversely due to small concentration of metal contaminants. Therefore a study has been undertaken to see the effect of metal contaminants on the thermal and oxidation stability of JCB. As PY was found to be the most effective antioxidant, therefore the effect of PY on metal contaminated JCB was studied in terms of oxidation and thermal stability. It was found that $350 \mathrm{ppm}$ dosage of PY was needed to improve the IP of iron and nickel contaminated JCB and minimum dosage of 400, 600, $600 \mathrm{ppm}$ of PY in manganese, cobalt and copper contaminated JCB was needed to meet EN-14112 specification for biodiesel oxidation stability. The corresponding value of activation energy and frequency factor for iron contaminated JCB is $54 \mathrm{KJ} / \mathrm{mol}$ and $125000 \mathrm{~min}^{-1}$ respectively. From the above analysis it is recommended to study the relation between oxidation and thermal stability of JCB.

\section{Acknowledgement}

The authors greatly acknowledge the financial support from Ministry of Human resource development (MHRD), Govt. of India in the form of research scholarship to carry out this work.

\section{References}

Chand P., Reddy C.V., Verkade J.G., Wang T. and Grewell D. 2009. Thermogravimetric Quantification of Biodiesel Produced via Alkali Catalyzed Transesterification of soybean oil. Energy and Fuels. Vol. 23, pp. 989-992.

Dantas M.B., Conceicao M.M., Fernandes V.J., Santos N.A., Rosenhaim R., Marques A.L.B., Santos I.M.G. and Souza A.G. 2007. Thermal and kinetic study of corn biodiesel obtained by the methanol and ethanol routes. J Therm Anal Calorim Vol. 87, No. 3, pp. 835-839.

Determination of ester and linolenic acid methyl ester contents, English version of DIN EN 14103 (2003).

Dunn R.O. 2005. Effect of antioxidants on the oxidative stability of methyl soyate (biodiesel), Fuel Processing Technology. Vol. 86, pp. 1071-1085.

Dunn R.O. 2006. Oxidative stability of biodiesel by dynamic mode pressurized-differential scanning calorimetry (P-DSC), American Society of Agricultural and Biological Engineers. Vol. 49, No. 5, pp. 1633-1641.

Freire L.M.S., Bicudo T.C., Rosenhaim R., Sinfronio F.S.M., Botelho J.R., Filho J.R.C., Santos I.M.G., Fernandes V.J., Filho N.R.A. and Souza A.G. 2009. Thermal investigation of oil and biodiesel from Jatropha curcas L, $J$ Therm Anal Calorim. DOI 10.1007/s10973-009-0055-y.

Fritsch C.W., Weiss V.E. and Anderson R.H. 1975. Effect of antioxidants on refined palm oil. Journal of the American Oil Chemists Society Vol. 52, No. 12.

Jingura R.M., Musademba D. and Matengaifa R. 2010. An evaluation of utility of Jatropha curcas L. as a source of multiple energy carriers. International Journal of Engineering, Science and Technology. Vol. 2, No. 7, pp. 115- 122.

Liang Y.C., May C.Y., Foon C.S., Ngan M.A., Hock C.C. and Basiron Y. 2006. The effect of natural and synthetic antioxidants on the oxidative stability of palm diesel, Fuel. Vol. 85, pp. 867-70.

Mittelbach M. and Schober S. 2003 The influence of antioxidants on the oxidation stability of biodiesel. Journal of the American Oil Chemists Society. Vol. 80, pp. 817-23.

Sarin R., Sharma M., Sinharay S. and Malhotra R.K. 2007. Jatropha-palm biodiesel blends: an optimum mix for Asia. Fuel. Vol. 86, No. 10-11, pp. 1365-1371.

Sarin A., Arora R., Singh N.P., Sharma M. and Malhotra R.K. 2009. Influence of metal contaminants on oxidation stability of Jatropha biodiesel. Energy. pp. 1-5.

Jain S. and Sharma M.P. 2008. Evaluation of engine performance on biodiesel from waste cooking oil. In: EIC Proceeding 2008.

Jain S. and Sharma M.P. 2010a. Prospects of biodiesel from Jatropha in India: A review. Renew Sust Energ Rev. Vol. 14, No. 2, pp. $763-771$.

Jain S. and Sharma M.P. 2010b. Stability of biodiesel and its blends: A review. Renew Sust Energ Rev. Vol. 14, No. 2, pp. 667678.

Jain S. and Sharma M.P. 2010c. Non- edible oil resources as alternative source of diesel, Presented in International Conference on Advances in Renewable Energy (ICARE- 2010) being held in National Institute of Technology Bhopal on 24- 26 June 2010, pp.717- 726.

Jain S. and Sharma M.P. 2010d. Kinetics of acid base catalyzed transesterification of Jatropha curcas oil. Bioresource Technology. Vol. 101, pp. 7701- 7706.

Wan Nik W.B., Ani F.N. and Masjuki H.H. 2005. Thermal stability evaluation of palm oil as energy transport media Energ Convers Manage. Vol. 46, pp. 2198- 2215. 


\section{Biographical notes}

Siddharth Jain received B. Tech. in Mechanical Engineering and M. Tech in Alternate Hydro Energy Systems from Indian Institute of Technology Roorkee, India. Currently he is pursuing Ph.D from IIT Roorkee in the field of stability of biodiesel and its impact on engine performance. His areas of interests are renewable energy technologies, integrated renewable energy systems, biomass and biofuels. He has published various papers in renowned international journals and conferences. Apart from this he is a reviewer of various international journals such as Bioresource Technology, Biomass and Bioenergy, Energy, Fuel Processing Technology, etc.

M.P. Sharma is Associate Professor at the alternate hydro energy centre at I.I.T. Roorkee. He did his Ph. D. from IIT Roorkee, India. His areas of interests are biomass and biofuel, conservation of rivers and lakes, integrated renewable energy technologies etc.

Received March 2011

Accepted June 2011

Final acceptance in revised form June 2011 